\title{
Development of Amperometric Laccase Biosensor through Immobilizing Enzyme in Magnesium-Containing Mesoporous Silica Sieve (Mg-MCM-41)/Polyvinyl Alcohol Matrix
}

\author{
Z. Dai, ${ }^{1,2}$ M. Q. Guo, ${ }^{1}$ X. J. Wang, ${ }^{1}$ H. F. Wang, ${ }^{1}$ and W. Y. Chen ${ }^{1,3}$ \\ ${ }^{1}$ College of Mechanics, Taiyuan University of Technology, Taiyuan 030024, China \\ ${ }^{2}$ College of Mining Technology of TUT, Taiyuan 030024, China \\ ${ }^{3}$ Institute of Applied Mechanics and Biomedical Engineering, Taiyuan University of Technology, Taiyuan 030024, China \\ Correspondence should be addressed to M. Q. Guo; gmgg82@sina.com
}

Received 5 September 2013; Accepted 22 October 2013; Published 12 January 2014

Academic Editor: Hui Xia

Copyright (C) 2014 Z. Dai et al. This is an open access article distributed under the Creative Commons Attribution License, which permits unrestricted use, distribution, and reproduction in any medium, provided the original work is properly cited.

\begin{abstract}
Magnesium-containing mesoporous silica sieve (Mg-MCM-41) provided a suitable immobilization of biomolecule matrix due to its uniform pore structure, high surface areas, fast electron-transfer rate, and good biocompatibility. Based on this, an amperometric biosensor was developed by entrapping laccase into the Mg-MCM-41/PVA composite matrix. Laccase from Trametes versicolor was assembled on a composite film of Mg-MCM-41/PVA modified Au electrode and the electrode was investigated by cyclic voltammetry, impedance spectroscopy, and chronoamperometry. The results indicated that the Mg-MCM-41/PVA/Lac modified electrode exhibited excellent catalytic activity towards catechol at room temperature in $\mathrm{pH} 4.8$ acetate buffer solution. The optimum experimental conditions of biosensor for the detection of catechol were studied in detail. Under the optimal conditions, the linear range was from 0.94 to $10.23 \mu \mathrm{M}$ with the sensitivity of $16.9227 \mathrm{~A} / \mathrm{M}$, the detection limit of $0.00531 \mu \mathrm{M}$, and the response time of less than 14 s. The Michaelis-Menten constant $\left(K_{M}^{\text {app }}\right)$ was estimated by Lineweaver-Burk equation and the $K_{M}^{\text {app }}$ value was about $1.01 \mu \mathrm{M}$. In addition, the biosensor exhibited high reproducibility and long-time stability. This work demonstrated that Mg-MCM-41/PVA composite provides a suitable support for laccase immobilization and construction of biosensor.
\end{abstract}

\section{Introduction}

Phenols, byproducts of large-scale production and use of man-made organics, will cause ecologically undesirable effects [1]. Their determination is of great practical importance in evaluating the toxicity of an environmental sample. Several methods have been developed for this purpose, including spectrophotometry and high performance liquid chromatography [2]. These methods are expensive, timeconsuming and sometimes require preconcentration. Many biosensors have been developed in the past using the catalytic activity of the redox enzymes such as tyrosinase, peroxidase, and laccase for phenol determination [3,4]. Laccase (Lac) does not require $\mathrm{H}_{2} \mathrm{O}_{2}$ as cosubstrate and any cofactors for its catalysis. Hence, the constructions of the biosensor are much easier. Lac-based biosensors have been employed for the determination of a broad range of phenolic compounds [2].

The development of enzyme-based biosensor with excellent performance requires advances in the materials and method available for enzyme immobilization. So it is necessary to develop ideal immobilization materials and efficient immobilization method. A series of organic compounds and inorganic materials have been used as enzyme immobilization matrices, such as carbon nanotube [5], magnetic mesoporous silica nanoparticles [6], polymer [7], and carbon-fiber $[8,9]$. According to previous papers [10-13], mesoporous silica sieve MCM-41 has been a promising immobilization matrix of enzyme due to its proper pore size, ordered uniform pore structure, proper surface characteristics, and good biocompatibility. However, the poor conductivity and 
film-forming property of mesoporous silica might influence the performance of the biosensor in amperometric detection.

In recent years, incorporation of the transition metal ions has caught more attention, which could enhance the optical, electrical, semiconducting, and surface properties of mesoporous materials [14-16]. However, the application of MCM-41 doping heteroatoms into the enzyme biosensor was rarely reported.

Accordingly, in the present study, a facile method was firstly used to incorporate magnesium in the MCM-41 frameworks (Mg-MCM-41), and the catechol biosensor was fabricated by immobilizing laccase in Mg-MCM-41/PVA composite film. The Mg-MCM-41/PVA/Lac film modified Au electrode was expected to improve some disadvantages of amperometric laccase biosensor.

\section{Experimental}

2.1. Reagents and Apparatus. Laccase from Trametes versicolor (EC1.1.3.4, 22.6 unit/mg) was purchased from Sigma Co. PVA with $1750 \pm 50^{\circ}$ of polymerization and $98 \%$ of degree of hydrolysis was supplied by Experimental Chemical Plant of Tianjin University (Tianjin, China). Magnesium sulfate $\left(\mathrm{MgSO}_{4}\right)$, sodium hydroxide $(\mathrm{NaOH})$, cetyltrimethylammonium bromide (CTAB), and tetraethylorthosilicate (TEOS) were purchased from Aldrich. All other chemicals were of analytical grade. $0.1 \mathrm{M}$ acetate buffer solution which consisted of $\mathrm{CH}_{3} \mathrm{COONa}$ and $\mathrm{CH}_{3} \mathrm{COOH}$ was employed as supporting electrolyte, and the $\mathrm{pH}$ value of desired solution was adjusted with $0.1 \mathrm{M} \mathrm{CH}_{3} \mathrm{COOH}$ or $0.1 \mathrm{M} \mathrm{NaOH}$. All solution was prepared with bidistilled water.

Nitrogen adsorption-desorption isotherm was measured at $77 \mathrm{~K}$ on a NOVA2000 Autosorb Sorption Analyzer (Quantachrome Corporation, USA). The specific surface area was calculated with the BET method. The pore size and pore volume were acquired from the adsorption branch of the isotherms by the $\mathrm{BJH}$ method. All the electrochemical measurements were carried out with a conventional threeelectrode system using a PARSTAT 2263 electrochemical workstation (Princeton Corporation, USA). The MCM41/PVA/Lac or Mg-MCM-41/PVA/Lac modified electrode was used as a working electrode with a saturated calomel electrode (SCE) as a reference electrode and a Pt wire as an auxiliary electrode. All experiments were carried out at room temperature.

2.2. Preparation of $M g-M C M-41$. The magnesium containing MCM-41, denoted hereafter as Mg-MCM-41, was synthesized as follows. The molar ratio of synthesis was 1 TEOS: $0.13 \mathrm{CTAB}: 0.02 \mathrm{MgSO}_{4}: 0.24 \mathrm{NaOH}: 66.7 \mathrm{H}_{2} \mathrm{O}$, which was in accordance with the previous literatures [18]. $2.3689 \mathrm{~g}$ CTAB was added to a solution $\left(0.48 \mathrm{~g} \mathrm{NaOH}\right.$ in $\left.60 \mathrm{~mL} \mathrm{H}_{2} \mathrm{O}\right)$ under stirring. When the solution became homogeneous, TEOS was added gradually in $30 \mathrm{~min}$, and then $\mathrm{MgSO}_{4}$ was added. The mixture was stirred constantly at $90^{\circ} \mathrm{C}$ for $48 \mathrm{~h}$ and then the sample was filtrated. Mg-MCM-41 was obtained after calcining at $540^{\circ} \mathrm{C}$ for $6 \mathrm{~h}$. Pure silica MCM-41 was also synthesized following the above-described procedure, without adding $\mathrm{MgSO}_{4}$ to the synthesis solution.
2.3. Immobilization of Laccase. Immobilization process was performed by the following method: $4 \mathrm{mg}$ MCM-41 or $4 \mathrm{mg}$ Mg-MCM-41 was dispersed into $5 \mathrm{~mL} 1 \mathrm{mg} / \mathrm{mL}$ laccase (in $\mathrm{pH} 4.8$ acetate buffer) solution by ultrasonic for $30 \mathrm{~min}$, respectively. The suspension was kept at $4^{\circ} \mathrm{C}$ for $24 \mathrm{~h}$ under stirring and then separated by centrifugation under the conditions of $8000 \mathrm{r} / \mathrm{min}$ for $15 \mathrm{~min}$. Finally, the obtained MCM-41/Lac and Mg-MCM-41/Lac were mixed with $100 \mu \mathrm{L}$ $0.3 \%$ PVA solution for $1 \mathrm{~h}$ at $4^{\circ} \mathrm{C}$ (MCM-41/PVA/Lac and MgMCM-41/PVA/Lac colloids). When not in use, the colloidal solutions were stored at $4^{\circ} \mathrm{C}$.

2.4. Electrode Modification. The Au electrode ( $4 \mathrm{~mm}$ diameter) was used as the substrate electrode. Before experiment, it was polished with $1.0,0.3$, and $0.05 \mu \mathrm{m}$ alumina slurry and rinsed thoroughly with double distilled water and then sonicated in double distilled water and allowed to dry at room temperature. Then, $5 \mu \mathrm{L}$ MCM-41/Lac/PVA and MgMCM-41/Lac/PVA colloids were dropped on the surface of pretreated $\mathrm{Au}$ electrodes and then allowed to dry under ambient condition. The thickness of Mg-MCM-41/Lac/PVA film was controlled by the volume of Mg-MCM-41/Lac/PVA solution used. Finally, the MCM-41/PVA/Lac and Mg-MCM41/PVA/Lac modified electrodes were obtained after rinsing with double distilled water twice. When not in use, the resulting electrodes were stored in $0.1 \mathrm{M}$ acetate buffer solution at $4^{\circ} \mathrm{C}$.

\section{Results and Discussion}

3.1. Characterization of $M g-M C M-41$. Figure 1 showed the results of Nitrogen adsorption-desorption isotherm and the pore size distribution curve at $77 \mathrm{~K}$ of Mg-MCM-41 and MCM-41. The isotherm was found to be of type IV with significant hysteresis loops, indicating that Mg-MCM-41 was mesoporous material [19]. As observed in Figure 1, high specific surface area of $949.3 \mathrm{~m}^{2} \mathrm{~g}^{-1}$ with the average pore diameter of $2.87 \mathrm{~nm}$ and the specific pore volume of $0.93 \mathrm{~cm}^{3} \mathrm{~g}^{-1}$ was obtained. From Table 1, it can be concluded that Mg-MCM-41 has larger pore size and pore volume than MCM-41. As a result, Mg-MCM-41 could adsorb more biomolecules and be suitable for the enzyme immobilization [17].

EIS was used to investigate the electrochemical properties of Mg-MCM-41 modified electrode surfaces [20]. By using $\mathrm{K}_{3}\left[\mathrm{Fe}(\mathrm{CN})_{6}\right] / \mathrm{K}_{4}\left[\mathrm{Fe}(\mathrm{CN})_{6}\right]$ redox couple as an electrochemical probe, the Nyquist plots of bare Au electrode, Mg-MCM41/PVA/Lac, and MCM-41/PVA/Lac modified electrode in the frequency range from $10^{-2} \mathrm{~Hz}$ to $10^{5} \mathrm{~Hz}$ were obtained in Figure 2. It was observed that, for the above-mentioned electrodes, the impedance spectra followed the theoretical shapes, a squeezed semicircle observed at high frequency, which corresponded to the electron-transfer limited process, followed by a linear part at the low frequency attributable to diffusion controlled electron-transfer process. In the low frequency region, no vertical increase in impedance on the imaginary part with decreasing the ac frequency was observed, which demonstrated that the electrodes exhibited no capacitive characteristics. 


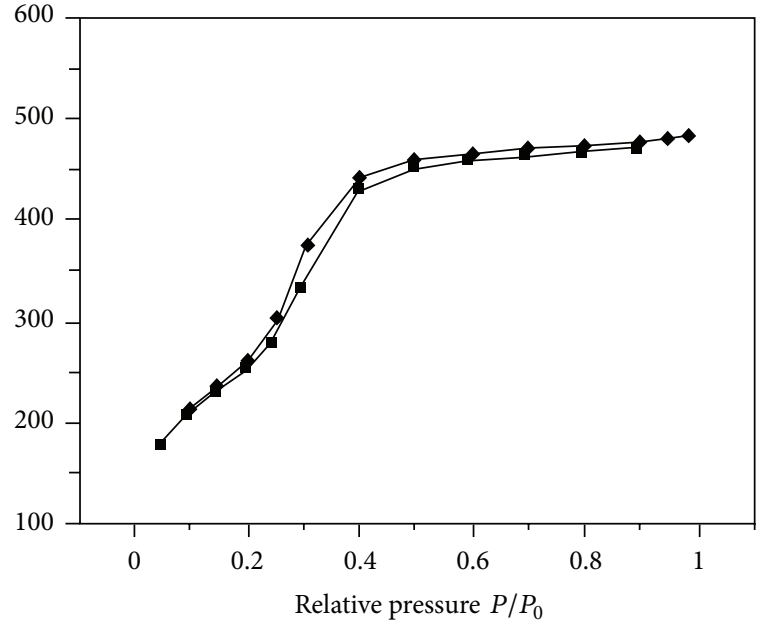

Adsorption

$\multimap$ Desorption

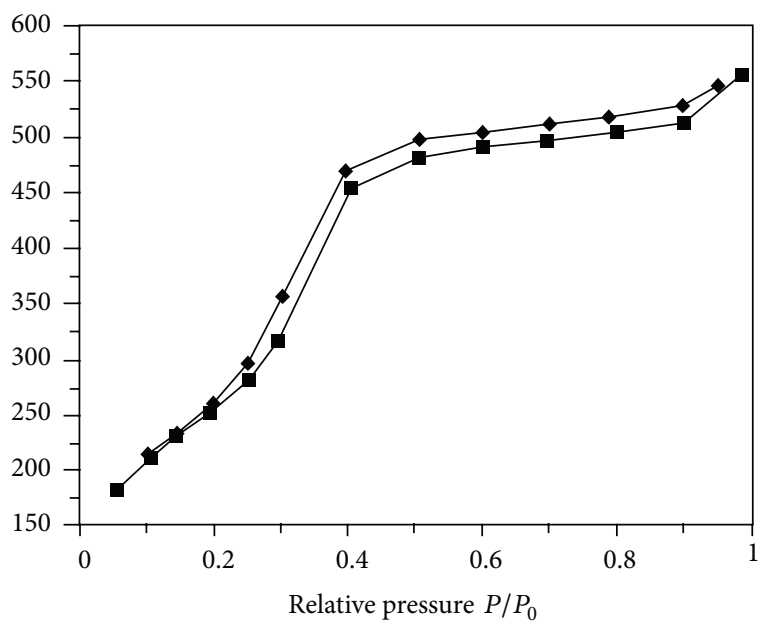

Adsorption

Desorption

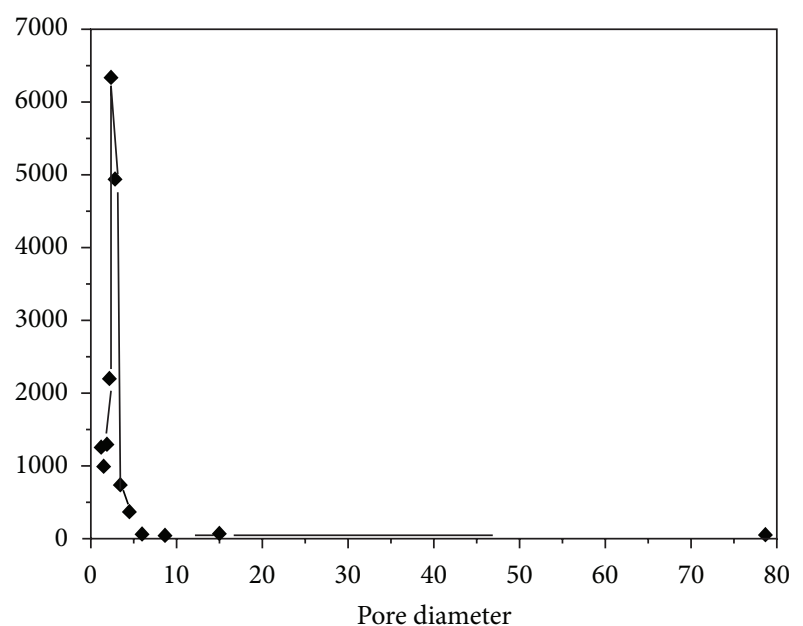

(a)

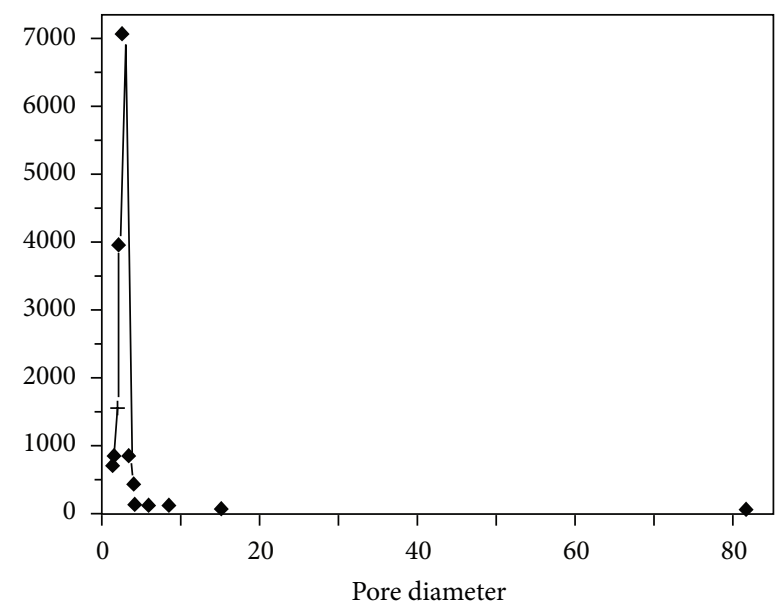

(b)

FIGURE 1: Nitrogen adsorption-desorption isotherm of Mg-MCM-41 and MCM-41.

TABLE 1

\begin{tabular}{lccc}
\hline Sample & BET surface area $\left(\mathrm{m}^{2} / \mathrm{g}\right)$ & Average pore diameter $(\mathrm{nm})$ & Pore volume $\left(\mathrm{cm}^{3} / \mathrm{g}\right)$ \\
\hline Mg-MCM-41 & 949.30 & 2.87 & 0.93 \\
MCM-41 & 951.2 & 2.47 & $0.814[17]$ \\
\hline
\end{tabular}

The respective semicircle diameters at the high frequency equalled the electron-transfer resistance (Rct) at the electrode surface. It was found that Rct of the Mg-MCM-41/PVA/Lac modified Au electrode was about $200 \Omega$, which was smaller than $300 \Omega$ of MCM-41/PVA/Lac modified Au electrode and $4500 \Omega$ of bare Au electrode. The results indicated that Mg-MCM-41/PVA could act as a superior electron-transfer interface between the EIS probe and electrode by accelerating the electron-transfer rate on the electrode surface effectively. In addition, the smaller Rct implied that the incorporation of $\mathrm{Mg}$ increased the electron-transfer rate on the electrodes surface effectively.

3.2. Voltammetric Behaviour of Catechol at Mg-MCM41/PVA/Lac Modified Electrode. Cyclic voltammetries (CVs) were employed to characterize the electrochemical behavior of laccase immobilized on the Mg-MCM-41 and MCM41. As shown in Figure 3, MCM-41/PVA/Lac and MgMCM-41/PVA/Lac modified Au electrode both exhibited redox behaviors, which could be ascribed to the oxidation 


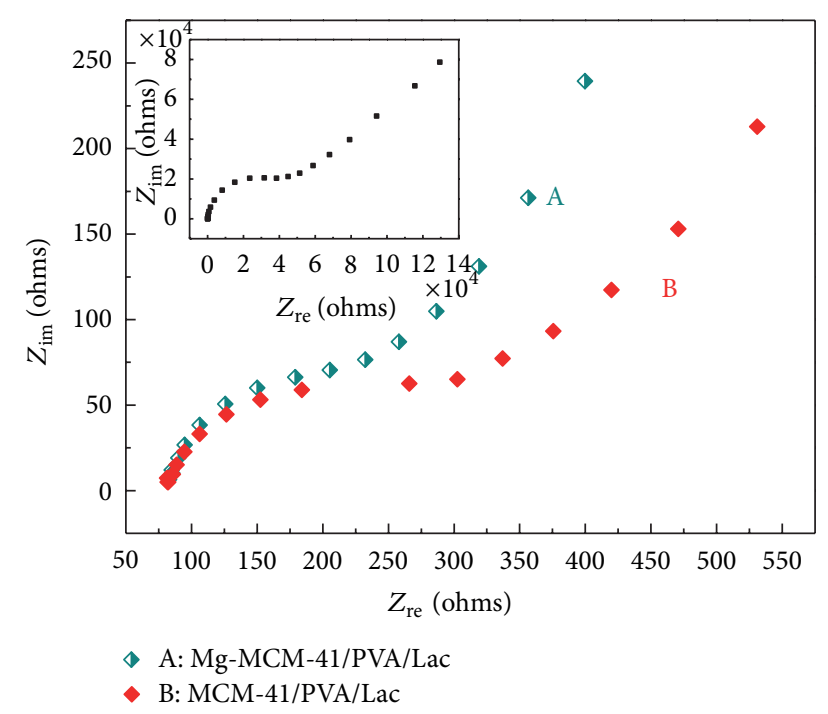

Figure 2: Nyquist plots of Mg-MCM-41/PVA/Lac/Au, MCM41/PVA/Lac/Au, and bare $\mathrm{Au}$ electrode (inset) in $5 \mathrm{mM} \mathrm{K}_{3}[\mathrm{Fe}$ $\left.(\mathrm{CN})_{6}\right] / \mathrm{K}_{4}\left[\mathrm{Fe}(\mathrm{CN})_{6}\right] / 0.1 \mathrm{M} \mathrm{KCl}$ solution.

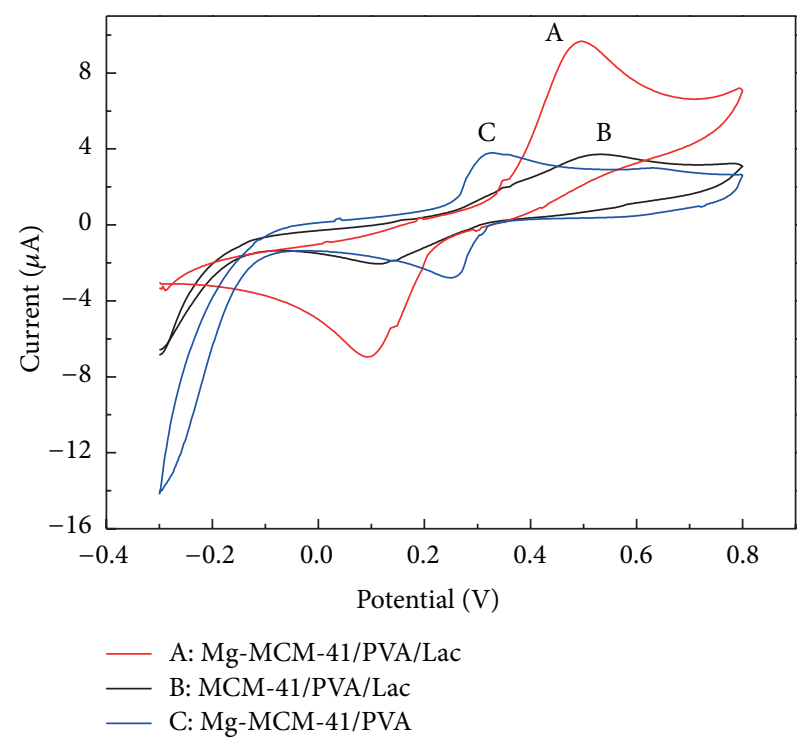

Figure 3: CVs of Mg-MCM-41/PVA/Lac/Au (A), MCM41/PVA/Lac/Au (B), and Mg-MCM-41/PVA (C) electrodes in $\mathrm{pH} 4.8$ acetate buffer solution at room temperature in presence of $0.05 \mathrm{mM}$ catechol, respectively $\left(50 \mathrm{mV} * \mathrm{~s}^{-1}\right)$.

of catechol. The anodic peak potential of Mg-MCM41/PVA/Lac modified electrode shifted to a more negative value and the cathodic peak potential shifted in a lower positive direction. In addition, the peak current of $\mathrm{Mg}$ MCM-41/PVA/Lac modified Au electrode was 2.6 times that of MCM-41/PVA/Lac modified Au electrode. The enhanced electrochemical behavior of Mg-MCM-41 may be attributed to the existence of $\mathrm{Mg}$ in Mg-MCM-41, which improved the electroactive of modified electrode.

Mg-MCM-41/PVA modified Au electrodes exhibited one pair of redox peaks ascribed to reduction of catechol, which

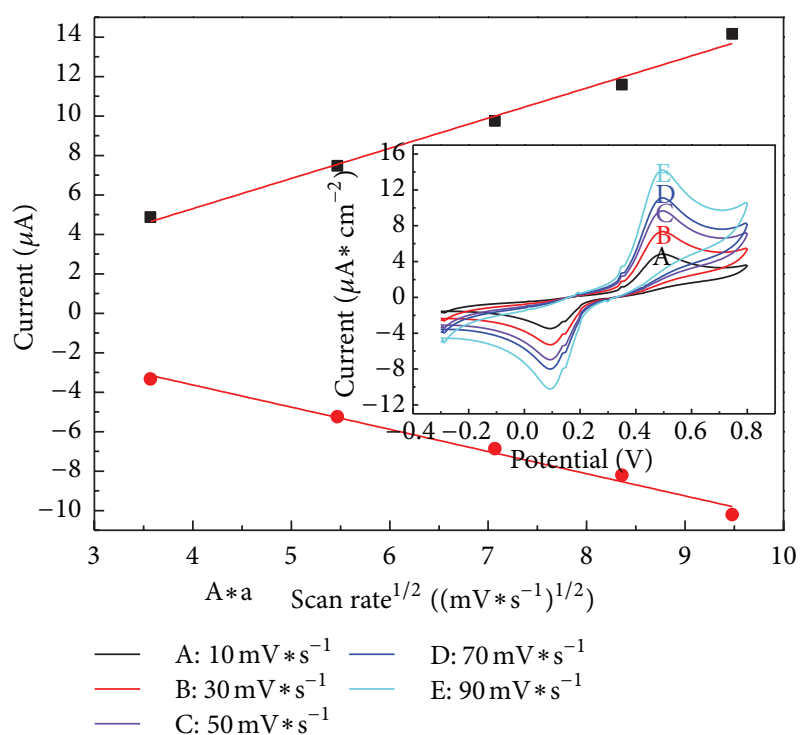

FIGURE 4: Current versus the square root of scan rate plots of $\mathrm{Mg}$ MCM-41/PVA/Lac/Au electrode in $\mathrm{pH} 4.8$ acetate buffer solution with $0.05 \mathrm{mM}$ catechol. Inset: CVs of the PVA/Lac/Au electrode in pH 4.8 acetate buffer solution with $0.05 \mathrm{mM}$ catechol at different scan rates from inner to outer: $10,30,50,70$, and $90 \mathrm{mV} * \mathrm{~s}^{-1}$.

proved the electrocatalytic properties of $\mathrm{Mg}-\mathrm{MCM}-41 . \mathrm{Mg}$ MCM-41/PVA/Lac also exhibited one well-defined redox peak, which means that catechol could carry through the direct electrochemical reaction on the surface of Mg-MCM41/PVA/Lac electrodes. The peak current of Mg-MCM41/PVA/Lac modified Au electrodes was 2.59 times that of Mg-MCM-41/PVA modified Au electrodes, which may be attributed to coreduction of catechol by the laccase immobilized in Mg-MCM-41 and Mg-MCM-41 or the activating effect of laccase by $\mathrm{Mg}$ incorporated in Mg-MCM-41.

Figure 4 displayed CVs of catechol on the Mg-MCM41/PVA/Lac/Au electrode at various scan rates. It was observed that the anodic and cathodic peak currents increased linearly with the square root of scan rate, which indicated a diffusion controlled process occurring on the surface of Mg-MCM-41/PVA/Lac/Au electrode.

3.3. Optimization of Biosensor's Working Conditions. To improve the performance of the biosensor, the effect of applied potential on the response of proposed biosensor to catechol was investigated. The effect of applied potential on the response current was shown in Figure 5(a). With the increase of the applied potential from $0.3 \mathrm{~V}$ to $0.45 \mathrm{~V}$, the response current increased accordingly, and when the applied potential was higher than $0.45 \mathrm{~V}$, the response current began to level off. Additionally, the interference from pyrogallol in the solution in the detection of catechol was relatively low at low applied potential. Thus, a potential of $0.45 \mathrm{~V}$ was selected as the working potential.

The effect of solution $\mathrm{pH}$ on response current was studied between $\mathrm{pH} 4.0$ and 6.0. As shown in Figure 5(b). The maximum response current was obtained at $\mathrm{pH}$ of 4.8 , which 


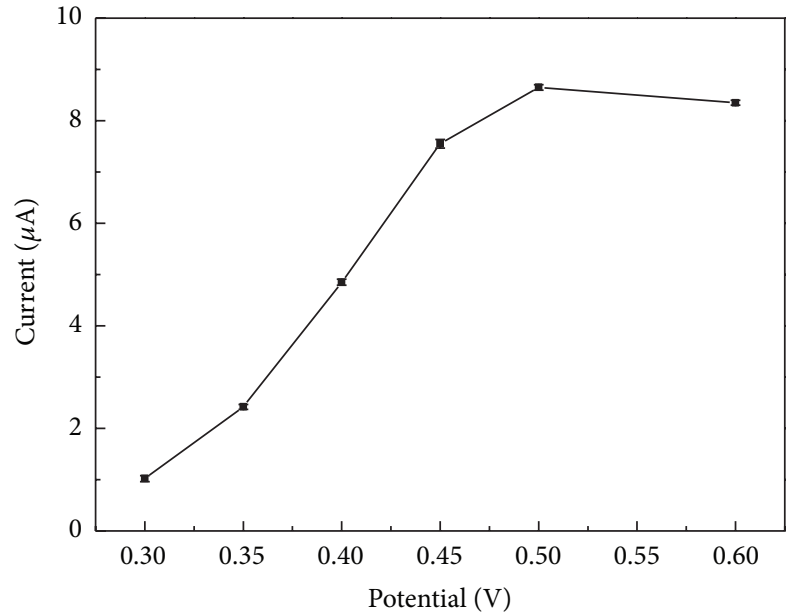

(a)

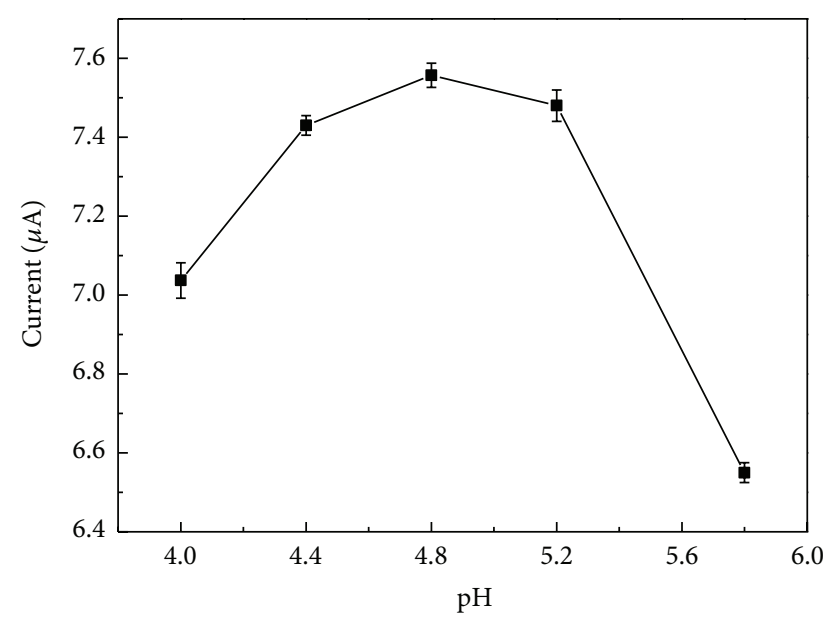

(b)

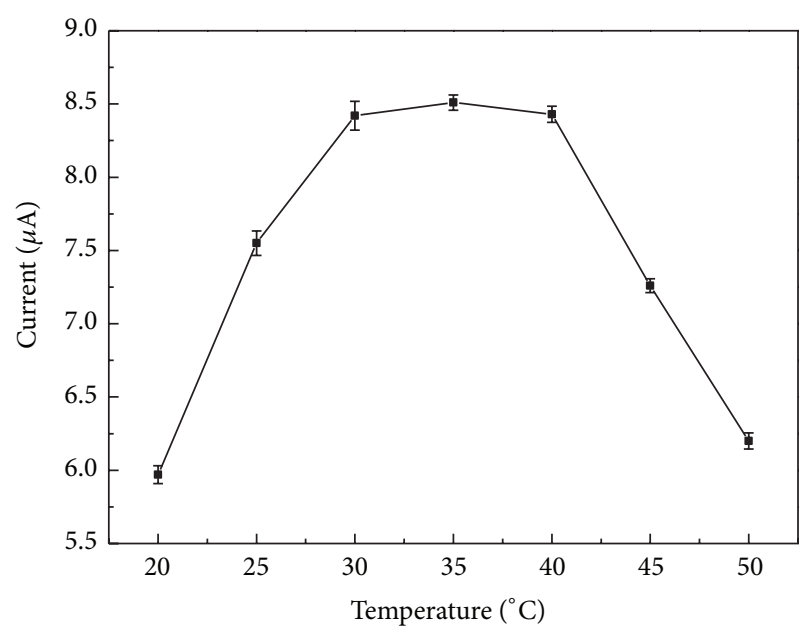

(c)

FIGURE 5: (a) Effect of applied potential on the current response of the Mg-MCM-41/PVA/Lac/Au electrode to $0.05 \mathrm{mM}$ catechol in $\mathrm{pH}$ 4.8 acetate buffer solution. (b) Effect of $\mathrm{pH}$ of acetate buffer solution on the current response of the Mg-MCM-41/PVA/Lac/Au electrode to $0.05 \mathrm{mM}$ catechol at $0.45 \mathrm{~V}$ (versus SCE). (c) Effect of temperature on the current response of the Mg-MCM-41/PVA/Lac/Au electrode to $0.05 \mathrm{mM}$ catechol in $\mathrm{pH} 4.8$ acetate buffer solution at $0.45 \mathrm{~V}$ (versus SCE). was similar to T. hirsuta Lac modified graphite electrode [21-23] and larger than T. versicolor Lac-modified carbon ceramic electrode [24]. Therefore, in this experiment, $\mathrm{pH}$ value of 4.8 was chosen for the detection of catechol.

The effect of temperature on the current response of $\mathrm{Mg}$ MCM-41/PVA/Lac modified Au electrodes was also studied in Figure 5(c). The current response increased with the increasing temperature and reached the maximum response at about $35^{\circ} \mathrm{C}$. Then the current began to decrease when the temperature was above $35^{\circ} \mathrm{C}$. The current decreased above $35^{\circ} \mathrm{C}$ may be caused by the thermal inactivation of laccase. Thus, the temperature of $35^{\circ} \mathrm{C}$ was chosen as the optimum temperature for the laccase biosensor.

3.4. Current-Time Response of Lac Immobilized on $\mathrm{Mg}$ $M C M-41 / P V A$. Figure 6(a) illustrated steady-state current response of $\mathrm{Mg}-\mathrm{MCM}-41 / \mathrm{PVA} / \mathrm{Lac} / \mathrm{Au}$ (A) and MCM41/PVA/Lac/Au (B) electrode at $0.45 \mathrm{~V}$ to $0.05 \mu \mathrm{M}$ catechol supported by acetate buffer solution ( $\mathrm{pH} 4.8)$ at room temperature, respectively. The response time of $\mathrm{Mg}-\mathrm{MCM}$ 41/PVA/Lac modified electrode was less than $14 \mathrm{~s}$ while MCM-41/PVA/Lac modified electrode was about $24 \mathrm{~s}$. In addition, the response current value $(0.85 \mu \mathrm{A})$ of $\mathrm{Mg}-\mathrm{MCM}-$ 41/PVA/Lac modified electrode was larger than $0.41 \mu \mathrm{A}$ of the MCM-41/PVA/Lac modified electrode under the same condition. This demonstrated that the electrode of laccase immobilized on Mg-MCM-41/PVA had a fast response rapidity and better sensitivity to catechol. Due to the smaller electron-transfer resistance of the Mg-MCM-41/PVA (as seen in Figure 2), Mg-MCM-41/PVA film had a faster electrontransfer process than that of MCM-41/PVA film.

Figure 6(b) showed the calibration curves of Mg-MCM41/PVA/Lac/Au (A) and MCM-41/PVA/Lac/Au (B) electrode to catechol. From Figure 6(b), it was observed that the response current increased with the increase of catechol concentration at low catechol concentration and at high concentration the current increased slowly and tended to stable when the concentration of catechol was high enough, which indicated the characteristic of Michaelis-Menten kinetics. As observed in Figure 6(b), the linear ranges of Mg-MCM41/PVA/Lac/Au and MCM-41/PVA/Lac/Au electrode were from 0.94 to $10.23 \mu \mathrm{M}$ and 0.46 to $4.01 \mu \mathrm{M}$, and the sensitivities were $16.92 \mathrm{~A} / \mathrm{M}$ and $12.61 \mathrm{~A} / \mathrm{M}$, respectively. The detection limit of the Mg-MCM-41/PVA/Lac/Au electrode was $0.0053 \mu \mathrm{M}$, which was lower than $0.0071 \mu \mathrm{M}$ of MCM41/PVA/Lac/Au and $0.67 \mu \mathrm{M}$ of $\mathrm{Cu}-\mathrm{OMC} / \mathrm{PVA} / \mathrm{Lac} / \mathrm{Au}$ electrode [18].

Kinetic studies of the immobilized laccase were performed at various concentrations of catechol. The apparent Michaelis-Menten constant $\left(K_{M}^{\mathrm{app}}\right)$ was calculated from the calibration plot using Lineweaver-Burk plot $(1 / i$ versus $1 /$ concentration). From the Lineweaver-Burk curves in Figure $6(\mathrm{c})$, the $K_{M}^{\mathrm{app}}$ can be calculated to be $1.01 \mu \mathrm{M}$ for Mg-MCM-41/PVA/Lac/Au electrode and 5.03 $\mu \mathrm{M}$ for MCM41/PVA/Lac/Au, respectively. The $K_{M}^{\text {app }}$ of $1.01 \mu \mathrm{M}$ was lower than $40.2 \mu \mathrm{M}$ of $\mathrm{Cu}-\mathrm{OMC} / \mathrm{PVA} / \mathrm{Lac} / \mathrm{Au}$ electrode [18] and $0.63 \mathrm{mM}$ of laccase immobilized on carbon-fiber electrodes [25]. The smaller $K_{M}^{\text {app }}$ value indicated that immobilized 


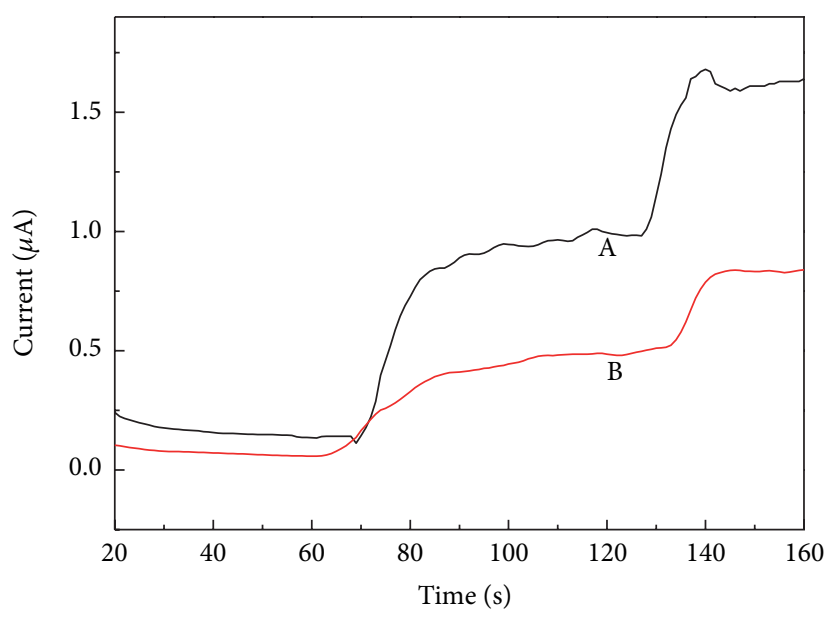

— A: Mg-MCM-41/PVA/Lac/Au electrode — B: MCM-41/PVA/Lac/Au electrode

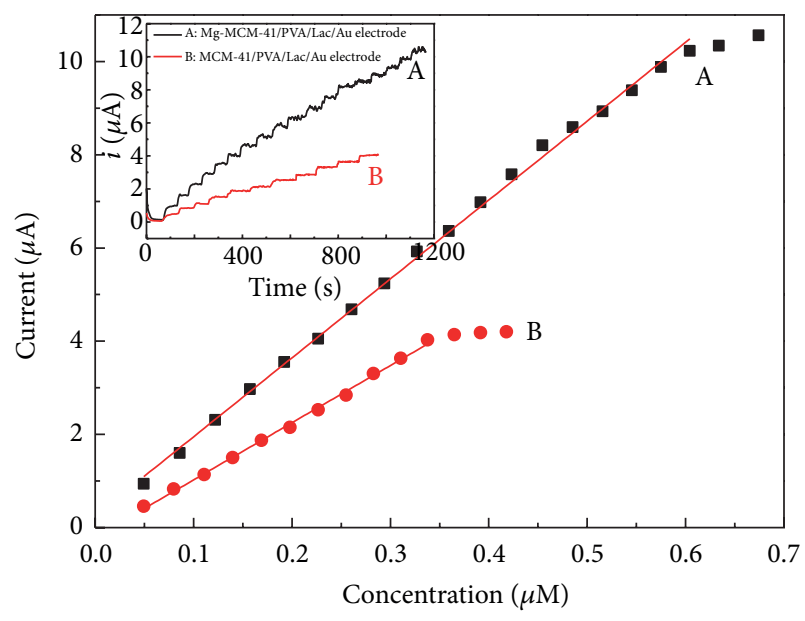

- A: Mg-MCM-41/PVA/Lac/Au electrode - B: MCM-41/PVA/Lac/Au electrode

(b)

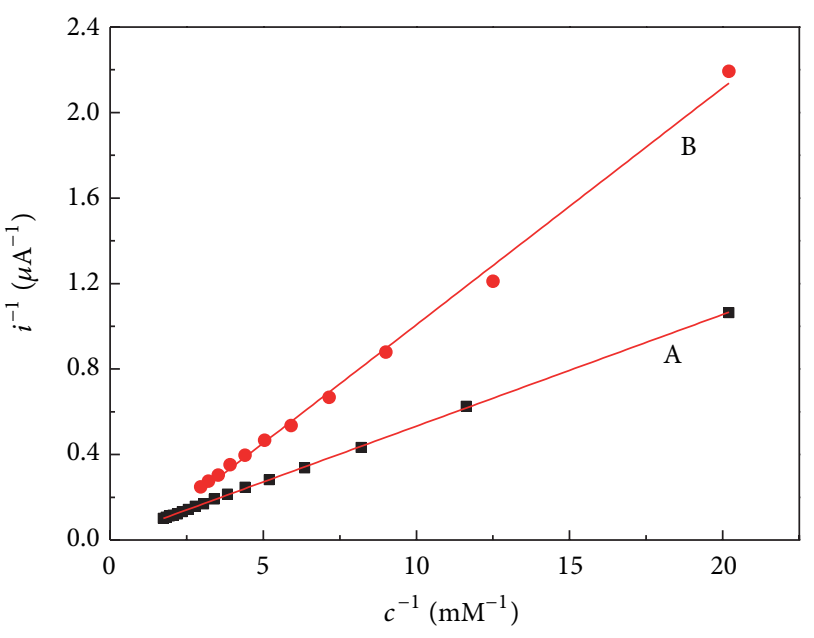

- A: Mg-MCM-41/PVA/Lac/Au electrode

- B: MCM-41/PVA/Lac/Au electrode

(c)

Figure 6: (a) The steady-state current response of Mg-MCM-41/PVA/Lac (A) and MCM-41/PVA/Lac (B) modified Au electrodes at 0.45 V to $0.05 \mathrm{mM}$ catechol supported by acetate buffer solution ( $\mathrm{pH} 4.8$ ) at room temperature, respectively. (b) The calibration curves of the Mg-MCM-41/PVA/Lac/Au electrode (A) and MCM-41/PVA/Lac/Au (B) at $0.45 \mathrm{~V}$ (versus SCE). Inset: amperometric responses of the Mg-MCM-41/PVA/Lac/Au electrode (A) and MCM-41/PVA/Lac/Au (B) on successive additions of obtained upon the successive addition $0.5 \mathrm{mM}$ catechol to stirred blank pH 4.8 acetate buffer solution at $0.45 \mathrm{~V}$ (versus SCE). (c) The Lineweaver-Burk curves of the Mg-MCM41/PVA/Lac/Au electrode (A) and MCM-41/PVA/Lac/Au (B) (versus SCE).

enzyme has higher enzymatic activity and implied that Mg-MCM-41 will enhance electrocatalysis of the substrate on the surface of electrodes.

3.5. Repeatability, Reproducibility, and Stability of the Lac Biosensor. The reproducibility of the Mg-MCM-41/PVA/ $\mathrm{Lac} / \mathrm{Au}$ electrode was evaluated by comparing the response currents of 10 enzyme electrodes prepared. The relative standard deviation (RSD) was $5.2 \%$ when $0.05 \mathrm{mM}$ catechol was determined. A reproducible current response with a RSD of $4.6 \%$ was observed for 30 successive assays of
$0.05 \mathrm{mM}$ catechol. The long-term stability was investigated by measuring a catechol solution intermittently, and the electrode was stored at $4^{\circ} \mathrm{C}$ by immersing in $0.1 \mathrm{M}$ acetate buffer solution when it was not in use. The results showed that the response current maintained more than $91 \%$ of its initial value after 30 days, indicating the good stability.

\section{Conclusions}

In the present study, a functionalized Mg-MCM-41 with good electrocatalytic properties has been synthesized. With 
the prominent advantages of large surface area, uniform mesopores, and remarkable electrocatalytic properties, an amperometric biosensor was developed by immobilizing laccase into the pores of Mg-MCM-41. The enzyme molecules assembled on Mg-MCM-41/PVA exhibited a high bioactivity and stability, and Mg-MCM-41 was demonstrated as suitable candidate to immobilize enzyme. The assembled laccase biosensor exhibited high sensitivity, low detection limit, good stability, and acceptable reproducibility for the determination of catechol. This work demonstrated that the Mg-MCM-41/PVA composite provides a support for laccase immobilization and construction of biosensors.

\section{Conflict of Interests}

The authors declared that there is no conflict of interests regarding the publication of this paper.

\section{Acknowledgments}

The authors gratefully acknowledge the financial support from the Natural Science Foundation of China (Grant no. 51301117) and the Natural Science Foundation for Young Scientists of Shanxi Province, China (Grant nos. 20130210031 and 2013021013-5).

\section{References}

[1] J. Kochana, P. Nowak, A. Jarosz-Wilkołazka, and M. Bieroń, "Tyrosinase/laccase bienzyme biosensor for amperometric determination of phenolic compounds," Microchemical Journal, vol. 89, no. 2, pp. 171-174, 2008.

[2] S. C. Fernandes, I. R. W. Z. de Oliveira, O. Fatibello-Filho, A. Spinelli, and I. C. Vieira, "Biosensor based on laccase immobilized on microspheres of chitosan crosslinked with tripolyphosphate," Sensors and Actuators B, vol. 133, no. 1, pp. 202-207, 2008.

[3] J. Kulys and R. Vidziunaite, "Amperometric biosensors based on recombinant laccases for phenols determination," Biosensors and Bioelectronics, vol. 18, no. 2-3, pp. 319-325, 2003.

[4] F. Vianello, A. Cambria, S. Ragusa, M. T. Cambria, L. Zennaro, and A. Rigo, "A high sensitivity amperometric biosensor using a monomolecular layer of laccase as biorecognition element," Biosensors and Bioelectronics, vol. 20, no. 2, pp. 315-321, 2004.

[5] Z. Song, J.-D. Huang, B.-Y. Wu, H.-B. Shi, J.-I. Anzai, and Q. Chen, "Amperometric aqueous sol-gel biosensor for lowpotential stable choline detection at multi-wall carbon nanotube modified platinum electrode," Sensors and Actuators B, vol. 115, no. 2, pp. 626-633, 2006.

[6] F. Wang, C. Guo, L.-R. Yang, and C.-Z. Liu, "Magnetic mesoporous silica nanoparticles: fabrication and their laccase immobilization performance," Bioresource Technology, vol. 101, no. 23, pp. 8931-8935, 2010.

[7] M. X. Chu, H. Kudo, T. Shirai et al., "A soft and flexible biosensor using a phospholipid polymer for continuous glucose monitoring," Biomedical Microdevices, vol. 11, no. 4, pp. 837-842, 2009.

[8] F. Barrière, P. Kavanagh, and D. Leech, "A laccase-glucose oxidase biofuel cell prototype operating in a physiological buffer," Electrochimica Acta, vol. 51, no. 24, pp. 5187-5192, 2006.
[9] Y. Liu, X. Qu, H. Guo, H. Chen, B. Liu, and S. Dong, "Facile preparation of amperometric laccase biosensor with multifunction based on the matrix of carbon nanotubes-chitosan composite," Biosensors and Bioelectronics, vol. 21, no. 12, pp. 2195-2201, 2006.

[10] H. Guo, N. He, S. Ge, D. Yang, and J. Zhang, "MCM41 mesoporous material modified carbon paste electrode for the determination of cardiac troponin i by anodic stripping voltammetry," Talanta, vol. 68, no. 1, pp. 61-66, 2005.

[11] Z. H. Dai, J. Ni, X. H. Huang, G. F. Lu, and J. C. Bao, "Direct electrochemistry of glucose oxidase immobilized on a hexagonal mesoporous silica-MCM-41 matrix," Bioelectrochemistry, vol. 70, no. 2, pp. 250-256, 2007.

[12] K. Yao, Y. Zhu, P. Wang, X. Yang, P. Cheng, and H. Lu, "ENFET glucose biosensor produced with mesoporous silica microspheres," Materials Science and Engineering C, vol. 27, no. 4, pp. 736-740, 2007.

[13] M. Miyahara, A. Vinu, and K. Ariga, "Adsorption myoglobin over mesoporous silica molecular sieves: pore size effect and pore-filling model," Materials Science and Engineering C, vol. 27, no. 2, pp. 232-236, 2007.

[14] M. C. R. Hernández, J. E. M. Wejebe, J. I. V. Alcántara, R. M. Ruvalcaba, L. A. G. Serrano, and J. T. Ferrara, "Immobilization of cytochrome P-450 on MCM-41 with different silicon/aluminum ratios," Microporous and Mesoporous Materials, vol. 80, no. 1-3, pp. 25-31, 2005.

[15] Y. Gao, T. A. Konovalova, T. Xu, and L. D. Kispert, "Electron transfer of carotenoids imbedded in MCM-41 and Ti-MCM-41: EPR, ENDOR, UV-Vis studies," Journal of Physical Chemistry B, vol. 106, no. 42, pp. 10808-10815, 2002.

[16] T. A. Konovalova, Y. Gao, R. Schad, L. D. Kispert, C. A. Saylor, and L.-C. Brunel, "Photooxidation of carotenoids in mesoporous MCM-41, NI-MCM-41 and AL-MCM-41 molecular sieves," Journal of Physical Chemistry B, vol. 105, no. 31, pp. 7459-7464, 2001.

[17] X. Xu, P. Lu, Y. Zhou, Z. Zhao, and M. Guo, "Laccase immobilized on methylene blue modified mesoporous silica MCM41/PVA," Materials Science and Engineering C, vol. 29, no. 7, pp. 2160-2164, 2009.

[18] X.-G. Zhao, J.-L. Shi, B. Hu, L.-X. Zhang, and Z.-L. Hua, "In situ formation of silver nanoparticles inside pore channels of ordered mesoporous silica," Materials Letters, vol. 58, no. 16, pp. 2152-2156, 2004.

[19] X. Yuan, W. Xing, S.-P. Zhuo et al., "Preparation and application of mesoporous Fe/carbon composites as a drug carrier," Microporous and Mesoporous Materials, vol. 117, no. 3, pp. 678-684, 2009.

[20] A. S. Baranski, T. Krogulec, L. J. Nelson, and P. Norouzi, "Highfrequency impedance spectroscopy of platinum ultramicroelectrodes in flowing solutions," Analytical Chemistry, vol. 70, no. 14, pp. 2895-2901, 1998.

[21] B. Haghighi, A. Jarosz-Wilkołazka, T. Ruzgas, L. Gorton, and A. Leonowicz, "Characterization of graphite electrodes modified with laccases from Trametes hirsuta and Cerrena unicolor and their use for flow injection amperometric determination of some phenolic compounds," International Journal of Environmental Analytical Chemistry, vol. 85, no. 9-11, pp. 753-770, 2005.

[22] A. I. Yaropolov, A. N. Kharybin, J. Emnéus, G. Marko-Varga, and L. Gorton, "Flow-injection analysis of phenols at a graphite 
electrode modified with co-immobilised laccase and tyrosinase," Analytica Chimica Acta, vol. 308, no. 1-3, pp. 137-144, 1995.

[23] R. S. Freire, S. Thongngamdee, N. Durán, J. Wang, and L. T. Kubota, "Mixed enzyme (laccase/tyrosinase)-based remote electrochemical biosensor for monitoring phenolic compounds," Analyst, vol. 127, no. 2, pp. 258-261, 2002.

[24] B. Haghighi, A. Rahmati-Panah, S. Shleev, and L. Gorton, "Carbon ceramic electrodes modified with laccase from Trametes hirsuta: fabrication, characterization and their use for phenolic compounds detection," Electroanalysis, vol. 19, no. 9, pp. 907917, 2007.

[25] R. S. Freire, N. Durán, and L. T. Kubota, "Effects of fungal laccase immobilization procedures for the development of a biosensor for phenol compounds," Talanta, vol. 54, no. 4, pp. 681-686, 2001. 

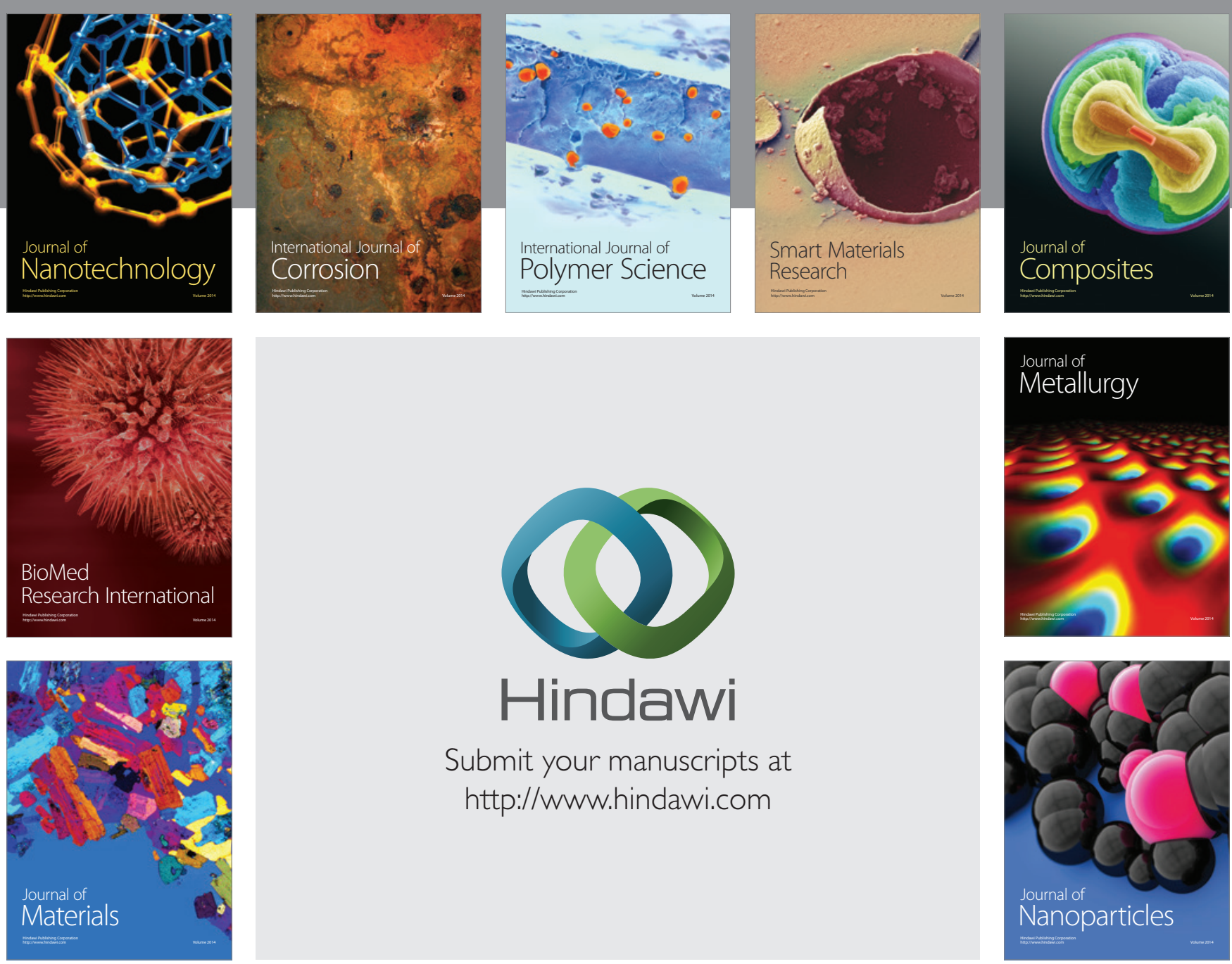

Submit your manuscripts at http://www.hindawi.com
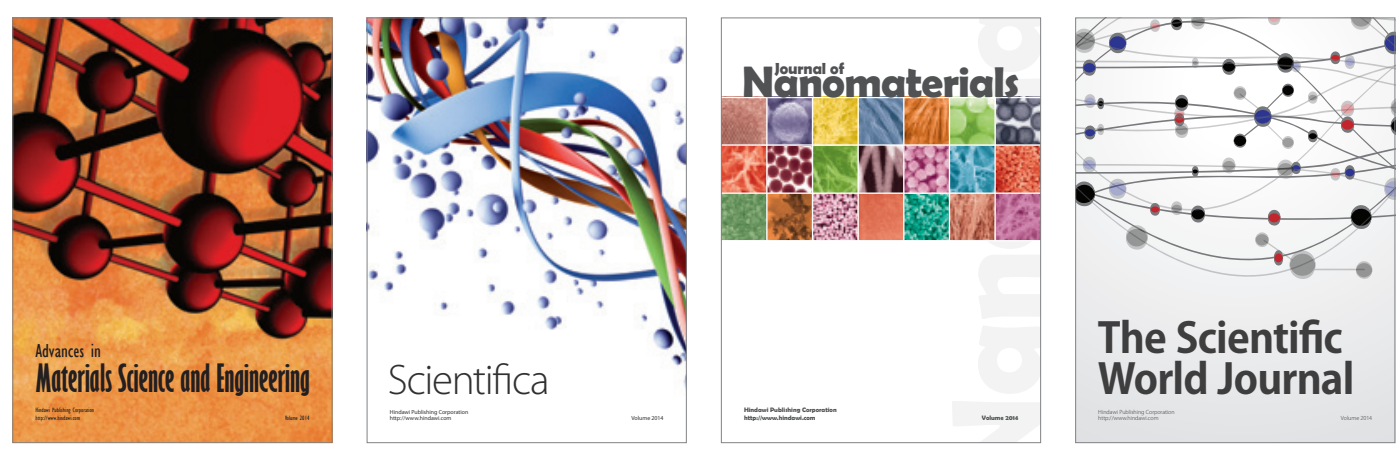

\section{The Scientific World Journal}
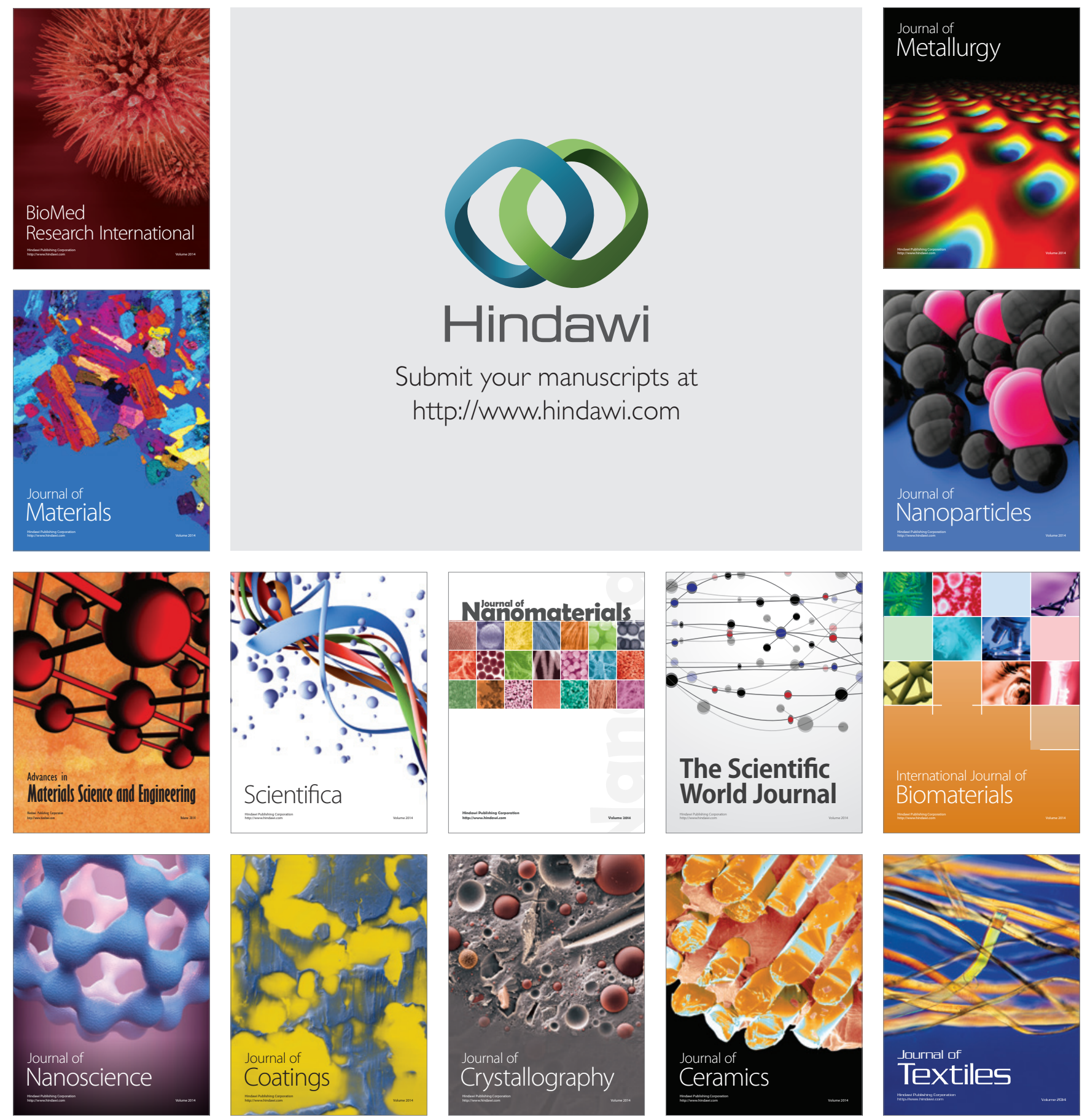